\title{
Efectos de la edad de adquisición de las palabras en denominación de imágenes en sujetos afásicos hablantes del español ${ }^{*}$
}

Effects of Age of Acquisition of Words on Images Naming Task in the Spanish-Speaking Aphasic Subjects

\author{
Pablo Godoy Ortega ${ }^{\mathrm{a}}$ \\ Universidad de Concepción, Chile \\ ORCID: http://orcid.org/0000-0002-6017-2571 \\ Bernardo Riffo Ocares \\ Universidad de Concepción, Chile \\ Katia Sáez Carrillo \\ Universidad de Concepción, Chile
}

a Autor de correspondencia. Correo electrónico: pablogodoy@udec.cl

Para citar este artículo: Godoy, P., Riffo, B., \& SáezCarrillo, K. (2017) (2017). Efectos de la edad de adquisición de las palabras en denominación de imágenes en sujetos afásicos hablantes del español. Universitas Psychologica, 16(4), 1-14. https://doi.org/1 0.11144/Javeriana.upsy16-4.eeap

\section{RESUMEN}

Se analizaron los efectos de la variable edad de adquisición de las palabras (EdA) en sujetos afásicos hablantes del español en una tarea de denominación de imágenes y su influencia en las propiedades de activación, inhibición y competencia léxicas. Veintidós sujetos afásicos completaron una tarea consistente en denominar 20 imágenes representativas de palabras de adquisición temprana (ATe) y 20 imágenes representativas de palabras de adquisición tardía (ATa). Las variables de precisión y tiempo de respuesta (TR) fueron analizadas, observándose un mayor número de aciertos y un menor TR ante imágenes ATe que ante imágenes ATa. A partir de los resultados se estableció que en sujetos afásicos la activación léxica de palabras correctas es mayor ante imágenes ATe que ante imágenes ATa.

Palabras clave

afasia; edad de adquisición; activación; inhibición y competencia léxicas.

\footnotetext{
ABSTRACT

The age of acquisition of words (AoA) effects in spanish-speaking aphasic subjects and its influence on the properties of lexical activation, inhibition and competition were analyzed in a naming task. Twenty two aphasic subjects completed a naming task with 20 images with early acquisition words (EA) and 20 images with late acquisition words (LA). Variables precision and response time (RT) were analyzed and the results showed a higher number of correct responses and a lower RT with EA images than those with LA images and it can be established that in aphasic subjects, lexical activation of right words to images is greater with EA images than with LA images.

Keywords

aphasia; age of acquisition; lexical activation; inhibition and competition.
} 
La afasia es entendida como una pérdida adquirida del lenguaje resultante de un daño cerebral, caracterizada por errores en la producción (parafasias), fallas en la comprensión y dificultades para hallar palabras (Kertesz, 1985). El signo clínico común de todas las afasias es la anomia, descrita como una incapacidad parcial o total para denominar normalmente elementos léxicos, ya sea en tareas de denominación por confrontación visual como también en habla continua (discurso oral) o ante solicitudes de evocación de palabras frente a descripciones (Goodglass, 1993; Jonkers \& Bastiaanse, 2007; Schuell, Jenkins, \& Carroll, 1962). Con respecto a los tipos de afasia, desde los inicios de la afasiología clásica, se ha utilizado la taxonomía fluente/no fluente para clasificar los diferentes tipos de afasia que se pueden observar luego de un daño neurológico.

Es así como, a partir de esta taxonomía podemos identificar dos tipos de afasia, considerando el desempeño que los sujetos evidencian en su discurso oral ante el parámetro de fluidez oral: afasias fluentes y afasias no fluentes. Estos dos grandes grupos de afasias se distinguen entre sí, no solo por la condición fluente/no fluente, sino que también se suman otras características que acompañan al nivel de fluidez oral, a saber: desempeño en comprensión auditiva, capacidad de evocación léxica, nivel de conservación de línea melódica y producción gramatical, entre otras. Asimismo, en el ámbito del procesamiento léxico, también se aprecian distinciones entre ambos grupos, las que siempre resultan interesantes de indagar, analizar y explicar a través de estudios psicolingüísticos.

El estudio del procesamiento léxico cuenta con diversas alternativas para medir las respuestas que los sujetos entregan ante la presentación de estímulos tanto auditivos como visuales. Las técnicas experimentales para el análisis del procesamiento léxico que habitualmente se utilizan son de dos tipos: pruebas on-line y pruebas off-line (Shapiro, Swinney, \& Borsky, 1998). Las pruebas on-line o tareas cronométricas fuerzan al sujeto a responder rápidamente sin equivocarse. Las variables dependientes son el acierto en la respuesta y el tiempo de respuesta o tiempo de reacción medido en milisegundos. Un mayor tiempo empleado por el sujeto para completar la tarea experimental se puede considerar una evidencia de que el procesamiento del estímulo presentado implicó un mayor consumo de recursos cognitivos.

En este ámbito, resulta interesante comparar los tiempos de respuesta ante estímulos que difieren en una u otra variable independiente, como la que se propone analizar en el presente estudio, a saber, la edad de adquisición de las palabras $(\mathrm{Ed} A)$, específicamente en una tarea de denominación por confrontación visual. El objetivo de esta técnica es medir el curso temporal de los procesos mentales que participan en una tarea de recuperación léxica de palabras para su producción. Es una prueba psicolingüística adecuada para sujetos afásicos por la alta sensibilidad que refleja en esta población, donde se van presentando imágenes que el sujeto debe nombrar en forma oral. El tiempo que tome la denominación, medido por un sensor que capta a través del micrófono el inicio de la producción, reflejará el grado de dificultad de procesamiento de cada palabra. Una tarea de nombrado a partir de una imagen presentada implica necesariamente que los sujetos deben acceder a su almacén léxico para recuperar la palabra que da nombre a la imagen percibida; podemos concluir, por tanto que, si ante una imagen como la de "silla" tarda menos tiempo en denominarla correctamente que ante una imagen como la de "pipa", efectivamente el procesamiento ante la primera imagen fue menos costoso. Este hecho puede ser explicado por una o más variables que pudiesen favorecer el procesamiento de la palabra "silla" por sobre la palabra "pipa", tales como la frecuencia léxica y la edad de adquisición en este caso.

\section{Modelos de procesamiento léxico}

El modelo de procesamiento léxico que guía la reflexión en el presente estudio es el modelo de Ellis y Young (1988), en el que se establece que cuando los individuos intentan 
nombrar un objeto, se activa un complejo set de eventos cognitivos. Estos eventos acontecen a través de pasos que preceden a otros en forma de cascada. Para explicar este modelo, se proponen los siguientes componentes o procesos psicológicos: 1. Análisis visual: El sujeto ve el objeto e identifica los rasgos físicos del objeto o imagen presentada, tamaño, forma y contorno. 2. Reconocimiento del objeto: El sujeto reconoce la imagen como familiar o establece que no es familiar. 3. Sistema semántico: El sujeto otorga un significado al objeto observado, incluyendo información tal como su función, objetos asociados (p. ej., lápiz-cuaderno), objetos coordinados (p. ej., auto-camión), ubicación y categoría (p. ej., medio de transporte, comida) 4. Léxico fonológico de salida: El sujeto recupera una representación fonológica abstracta del nombre del objeto. Con esta información el sujeto puede saber con qué fonema se inicia la palabra, cuántos fonemas y sílabas posee y con qué palabra rima. 5. Nivel fonémico: El sujeto recupera, a través de un mecanismo de selección correcta y ordenada, los fonemas que componen la palabra. Luego se activará la programación motora (o mecanismo pre-motor) para así generar la activación requerida para una correcta ejecución motora de la palabra, necesaria para el habla.

Una forma de describir cómo se produce el acceso léxico en las afasias es haciendo referencia a cada una de las manifestaciones clínicas características de estas, basándose en los modelos de producción de la palabra y sus respectivos niveles involucrados (nivel semántico, nivel léxico y nivel fonológico), así como también en las propiedades léxicas de activación, inhibición y competencia. El acceso a una palabra, tanto para un sujeto sin alteración del lenguaje como para un sujeto afásico, implica siempre un control de los competidores, control que evidentemente es más complejo en caso de lesión neurológica. La recuperación de una palabra en producción requiere una activación de la palabra objetivo así como también que esta sea seleccionada entre otras palabras activadas simultáneamente, también conocidas como competidores, proceso que se ve afectado por una variedad de factores externos e internos. Entre los factores internos destacan las características propias de las palabras, en relación con otras que comparten la misma vecindad léxica, así como también la eficiencia con que los procesos léxicos operan en un individuo. Los factores externos incluyen aspectos de la tarea, tales como el grado en que las respuestas son restringidas o la presencia o ausencia de demandas que compiten en los recursos del procesamiento (Gordon \& Kindred, 2011). Los modelos contemporáneos de acceso léxico en producción del habla proponen que la activación en cascada se genera automáticamente desde las representaciones semánticas del mensaje a las unidades léxicas correspondientes y, desde ahí, a las unidades fonológicas. Esta propagación genera una coactivación de ítems que comparten rasgos semánticos con el ítem buscado. Algunos modelos proponen también que la activación se propaga interactivamente, devolviéndose desde las unidades fonológicas a las léxicas y desde las unidades léxicas a las semánticas (Dell, Schwartz, Martin, Saffran, \& Gagnon, 1997). A consecuencia de ello, en el intento de la recuperación de la palabra, muchos ítems no buscados llegan a estar activos y el sistema debe introducir los mecanismos que permitan focalizarse rápidamente en la palabra deseada. En tareas que consideran más de una palabra, la proliferación de activación aumenta desde las palabras previamente producidas o activadas, fenómeno que puede interferir con los estímulos posteriores y las respuestas requeridas frente a estos. Obviamente, este es un desafío que, tal como se señaló antes, debe ser resuelto en el discurso natural; dicha resolución, sin embargo, tiende a ser compleja en el contexto del discurso de un sujeto con una lesión que ha afectado su desempeño lingüístico.

Para ejemplificar esto, tomaremos como referencia un signo clínico recurrente en gran parte de los sujetos que padecen afasia: la perseveración verbal. Recordemos que la perseveración verbal es la persistencia de la producción de una respuesta previamente entregada ante un estímulo externo o interno. El modelo de activación por difusión de Dell (1986) 
ofrece una explicación para las perseveraciones verbales que consiste en señalar que los errores de perseveración verbal se producen por el mismo mecanismo ordinario que los errores de sustitución por otra palabra, pero que tienen una pequeña ventaja por sobre el resto de las otras representaciones que compiten, al presentar un nivel de activación en reposo que se mantiene elevado por activación previa o reciente. Así también, algunas sustituciones que no son consideradas perseveraciones verbales pudiesen surgir a partir de fenómenos de insuficiente inhibición de un vecino léxico de una respuesta previa (Figura 1).

\section{Figura 1.}

Sustitución de una palabra en una tarea de denominación por confrontación visual.

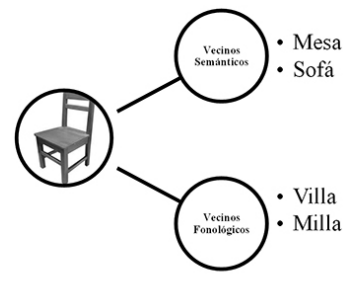

/'si.ya/

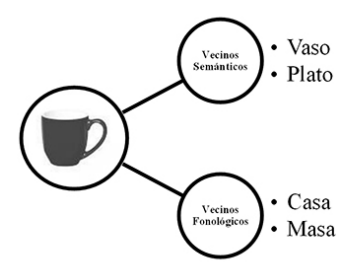

/so.'fa/
La respuesta previa /'si.ya/ se manifiesta en

la segunda respuesta a través de la activación de un vecino semántico de la palabra del primer estímulo. En este caso, si bien no se considera una perseveración verbal, la respuesta/so.' fa/ ante el estímulo visual "taza", surge producto de la insuficiente inhibición de un vecino léxico que comparte rasgos semánticos con la respuesta previa. Fuente: elaboración propia.

\section{Edad de adquisición como variable léxica}

En el ámbito de la afasiología, es ampliamente extendido el conocimiento de que los pacientes afásicos rinden mejor ante determinados estímulos que ante otros. Es así como se establece la noción de que los estímulos visuales (imágenes u objetos concretos) representados por palabras de alta frecuencia suelen ser de menor dificultad para los sujetos afásicos, lo que se representa en una mayor cantidad de aciertos y, a la vez, en menores tiempos de respuesta.
Desde mediados de la década de los 60, una nueva variable léxica y sus efectos en las respuestas de sujetos afásicos ante tareas de denominación comenzó a ser considerada: la edad de adquisición de la palabra (EdA) (Rochford \& Williams, 1965). La EdA de la palabra refleja el momento en el desarrollo cuando una palabra es adquirida para su uso en producción. Se han utilizado diversos procedimientos para establecer índices de edad de adquisición en grupos de palabras. Un procedimiento subjetivo, cuyos índices han evidenciado alta validez al ser confrontados con índices provenientes de estudios más objetivos es la aplicación de una encuesta a adultos normales a través de la cual el encuestado establece la edad en que estima haber aprendido cada una de las palabras presentadas. Se utiliza una escala de 1 a 11, donde 1 corresponde a antes de los 2 años de edad; 2, después de los 2 años de edad y asî sucesivamente (Cuetos, Ellis, \& Alvarez, 1999). Si bien ha existido investigación al respecto, tanto en personas normales como con afasia, no hay abundante literatura que haya considerado la variable de edad de adquisición en recuperación léxica en sujetos afásicos.

En el estudio de Rochford y Williams (1965), sometieron a 32 sujetos con pérdida del lenguaje por daño cerebral a una tarea de denominación de 7 objetos. Se constató que el porcentaje de respuestas correctas estaba relacionado con la edad en que se adquieren las palabras, estableciendo que las palabras que primero se adquieren son las últimas que se pierden. En un estudio de Nickels y Howard (1995), el foco de atención fue puesto en establecer las variables que determinan la probabilidad de que una tarea lingüística pueda ser desarrollada correctamente por un paciente afásico, y a partir de este establecimiento proponer los niveles en los que los procesos se están afectando. El objetivo fue determinar si las dificultades que los sujetos afásicos presentan con determinadas palabras pueden ser atribuidas a las propiedades de dichas palabras. Se han considerado diversos factores cuyos efectos pueden jugar un rol significativo en el desempeño de un sujeto afásico: frecuencia léxica, edad de adquisición 
de la palabra, imaginabilidad, operatividad, nivel de concreción y longitud de la palabra. Por sobre todas estas variables, se ha encontrado que la frecuencia léxica de la palabra posee los efectos más importantes en el desempeño léxico de los sujetos afásicos (Butterworth, Howard, \& McLaughlin, 1984). Sin embargo, otros estudios (Brown \& Watson, 1987; Carroll \& White, 1973) muestran que en realidad los efectos favorecedores de la frecuencia léxica en tareas de acceso léxico son más bien atribuibles a la edad de adquisición, aunque se establece la distinción de que estos efectos son más evidentes en tareas de denominación y de lectura de palabras, y no en tareas de reconocimiento.

Se concluye, por tanto, que la variable de EdA logra predecir mejor el desempeño en los procesos de producción de la palabra que en los de comprensión. Por ejemplo, su efecto significativo en la velocidad de denominación de objetos no se ha observado en tareas de categorización de imágenes, donde los sujetos debían señalar si estas eran artificiales o naturales (Morrison, Ellis, \& Quinlan, 1992). Morrison y colaboradores (1992) usaron estos resultados para argumentar que los efectos de la $\mathrm{EdA}$ residen en la recuperación y/o la codificación de las formas fonológicas de las palabras. A diferencia de la frecuencia léxica, la $\mathrm{EdA}$ contribuye solo en la disminución de errores fonológicos, por lo que su efecto se centraría más bien en la selección de las unidades fonológicas necesarias para recuperar una palabra. Así también, en un estudio en que se analizó el desempeño de un paciente afásico en tareas de denominación escrita y hablada (Hirsh \& Ellis, 1994), se encontró un importante efecto de la edad de adquisición en la precisión de las respuestas, controlando las variables de frecuencia léxica, imaginabilidad, familiaridad, grado de concreción y longitud de la palabra. En este estudio de caso único, el procesamiento léxico se vio afectado por la variable de edad de adquisición, donde las palabras de adquisición temprana se procesaron con mayor precisión que aquellas palabras de adquisición tardía en tareas de denominación a través del habla, de la escritura y de lectura en voz alta. Se utilizó una combinación de análisis de regresión múltiple y de diseños factoriales, en un esfuerzo por establecer que la edad de adquisición fue la variable que influyó en las tareas de producción del habla y no precisamente la frecuencia léxica de palabras o imaginabilidad (ambos factores con los que la edad de adquisición está altamente correlacionada). En la base del patrón de desempeño observado y de estudios de los efectos de la edad de adquisición en el procesamiento léxico en sujetos normales, se propone que la edad de adquisición afecta el proceso de recuperar las formas fonológicas de las palabras, observándose que las representaciones fonológicas adquiridas tempranamente son más robustas y menos vulnerables a las lesiones cerebrales que las representaciones adquiridas tardíamente.

Es evidente que una variedad de factores pueden determinar el cómo un sujeto afásico puede lograr la recuperación de un nombre de una imagen, dado que muchos de estos factores están fuertemente interrelacionados y es difícil separar sus efectos. De hecho, muchos de los estudios mencionados previamente no tomaron en cuenta las correlaciones entre las variables. Por lo tanto, algunos de los efectos significativos que se mencionan pueden ser debidos a la confusión de variables interrelacionadas y no necesariamente ser un efecto independiente de la variable específica bajo análisis. Por ejemplo, Feyereisen y colaboradores (Feyereisen, Van der Borght, \& Seron, 1988) no encontraron un efecto significativo independiente en la variable de operatividad al controlar la variable de EdA o la variable de familiaridad. Por su parte, Morrison et al. (1992) observaron que la frecuencia léxica no presentaba un efecto independiente sobre la nominación de imágenes cuando se consideraban la EdA, longitud e imaginabilidad.

Una forma de abordar el problema de las grandes correlaciones entre las variables es tomar un grupo específico de palabras que se corresponden en cuanto a una variable (o más) y que difieren en la variable que está bajo evaluación; la dificultad con este enfoque es que las palabras que son, por ejemplo, emparejadas en términos de igual frecuencia léxica y que difieren en EdA, a menudo pueden resultar muy 
escasas (Cutler, 1981). Una alternativa es el uso de un análisis de regresión múltiple. Esta opción permite analizar las correlaciones de los atributos de las palabras entre ellas y con el rendimiento de denominación y así poder determinar la contribución relativa de cada atributo en la predicción del rendimiento.

En este mismo plano, resulta interesante distinguir con precisión las propiedades de activación, inhibición y competencia léxicas que se manifiestan en las tareas de denominación y cómo estas se ven influenciadas por la variable de EdA. Al respecto, Biegler, Crowther y Martin (2008) proporcionan evidencia adicional que aclara los mecanismos implicados en la selección de información fonológica y semántica durante la producción de la palabra. Se reportan dos pacientes con daño cerebral que fueron claramente exitosos en la nominación aislada de imágenes, pero presentaron fracasos al nominar series de imágenes semánticamente relacionadas. Muchos resultados indican que los déficits afectan la selección de la fonología de la palabra y que los errores se deben a una excesiva activación de palabras relacionadas semánticamente, las que bloquean la selección de la palabra correcta, llevando a elegir una errónea. Esta sobreactivación se explica a partir de una falta de inhibición de palabras previamente producidas o relacionadas semántica o fonológicamente con la palabra buscada. Bajo circunstancias normales, no se produciría esta falta de inhibición, lo que reduce la activación de las palabras que previamente se han producido $\mathrm{u}$ otras activadas mediante difusión por similitud semántica o fonológica. Finalmente, esto hace posible la selección de la próxima palabra y minimiza la competencia léxica.

Una producción frecuente resultante de esta falta de inhibición en los sujetos afásicos, tal como se señaló antes, es la perseveración verbal. Con respecto a las propiedades de inhibición y activación, los autores plantean que lo que se inhibe (o deja de activarse) es la forma fonológica de la palabra, al menos en habla seguida o conversacional, ya que la información semántica debiese mantenerse activa considerando que habitualmente hablamos sobre temas vinculados que siguen latentes. A partir de los hallazgos, resulta plausible formularse la pregunta acerca de cuál es la magnitud de los efectos de la variable $\mathrm{EdA}$, en una tarea de recuperación léxica como la denominación de imágenes por confrontación visual, cuestión que el presente estudio intenta responder.

En este contexto, el presente trabajo tiene como principal propósito determinar si la EdA constituye una variable léxica relevante en la producción lingüística de pacientes afásicos en grado tal que permita explicar diferencias de desempeño con respecto a palabras de adquisición temprana con respecto a palabras de adquisición más tardía. Siguiendo esta lógica, se espera mayor precisión y menor tiempo de respuesta frente a estímulos de más temprana EdA que ante aquellos de EdA tardía. De este modo, la investigación se propone contribuir a los estudios psicolingüísticos de orientación clínica en orden a probar nuevas variables que permitan comprender mejor el procesamiento del lenguaje en la afasia y, específicamente, el papel que las representaciones fonológicas desempeñan en la producción léxica de los pacientes.

\section{Método}

\section{Diseño}

Se realizó un estudio de tipo cuasiexperimental que incluyó como variables independientes la edad de adquisición de las palabras, la frecuencia léxica y el tipo de afasia. Las variables dependientes fueron la precisión de respuestas (correcta/incorrecta) y el tiempo de respuesta de las respuestas correctas.

\section{Participantes}

El grupo de estudio estuvo conformado por un total de 22 sujetos afásicos, 12 hombres $(54.5$ $\%)$ y 10 mujeres (45.5\%), con un rango de edad entre 43 y 78 años y una media de edad de 58.1 años (10.1). Con respecto al tipo de afasia, 14 sujetos eran portadores de una afasia 
fluente ( 8 sujetos con lesión perisilviana y 6 con lesión extrasilviana) y 8 sujetos eran portadores de una afasia no fluente (6 sujetos con lesión perisilviana y 2 con lesión extrasilviana). Con respecto a la distinción de lesiones perisilvianas y extrasilvianas, es importante precisar que esta surge a partir de la topografía de la lesión y la conservación de la capacidad de repetición. Las afasias con lesiones extrasilvianas, también conocidas como transcorticales, se producen por daños predominantemente situados fuera de la zona del lenguaje o área perisilviana y presentan conservación en la capacidad de repetición. Por su parte, las afasias con lesiones perisilvianas se producen por lesiones en la zona perisilviana y presentan un importante déficit en la capacidad de repetición (Ardila, 2006). Los participantes eran pacientes de diversos centros de atención del servicio público de salud de la provincia de Concepción (Chile), todos los cuales contaban con el diagnóstico de afasia, establecido a través de la aplicación del Protocolo de Evaluación del Lenguaje para Pacientes Afásicos (González, 2001) e informado por fonoaudiólogo tratante, según se constató en la ficha clínica (Tabla 1).

\section{TABLA 1}

Características del grupo en estudio

\begin{tabular}{|c|c|c|c|}
\hline Sujeto & $\begin{array}{c}\text { Tiempo Post- } \\
\text { AVE }^{*}\end{array}$ & Diagnóstico Fonoaudiólógico & Subgrupo ** \\
\hline 1 & 18 & $\begin{array}{l}\text { - Afasia no fluente mixta moderada } \\
\text { - Apraxia del habla leve }\end{array}$ & NF_P \\
\hline 2 & 2 & $\begin{array}{l}\text { - Afasia global severa } \\
\text { - Apraxia del habla moderada }\end{array}$ & NF_P \\
\hline 3 & 24 & - Afasia anómica leve & F_E \\
\hline 4 & 44 & $\begin{array}{l}\text { - Afasia no fluente mixta moderada } \\
\text { - Apraxia del habla moderada }\end{array}$ & NF_P \\
\hline 5 & 1 & - Afasia de Wernicke severa & F_P \\
\hline 6 & 2 & - Afasia de conducción leve & F_P \\
\hline 7 & 13 & - Afasia de Wernicke severa & F_P \\
\hline 8 & 2 & - Afasia de conducción moderada & F_P \\
\hline 9 & 6 & - Afasia de conducción moderada & F_P \\
\hline 10 & 20 & - Afasia de conducción severa & F_P \\
\hline 11 & 1 & - Afasia anómica leve & F_E \\
\hline 12 & 64 & - Afasia anómica leve & F_E \\
\hline 13 & 2 & - Afasia anómica severa & F_E \\
\hline 14 & 4 & - Afasia de conducción moderada & F_P \\
\hline 15 & 1 & - Afasia de conducción leve & F_P \\
\hline 16 & 48 & - Afasia anómica leve & F_E \\
\hline 17 & 21 & - Afasia extrasilviana mixta mod. & NF_E \\
\hline 18 & 14 & $\begin{array}{l}\text { - Afasia no fluente mixta moderada } \\
\text { - Apraxia del habla moderada a severa }\end{array}$ & NF_P \\
\hline 19 & 24 & $\begin{array}{l}\text { - Afasia no fluente mixta moderada } \\
\text { - Apraxia del habla moderada }\end{array}$ & NF_P \\
\hline 20 & 1 & - Afasia transcortical mixta severa & NF_E \\
\hline 21 & 11 & - Afasia Anómica leve & F_E \\
\hline 22 & 33 & $\begin{array}{l}\text { - Afasia no fluente mixta severa } \\
\text { - Apraxia del habla moderada } \\
\end{array}$ & NF_P \\
\hline
\end{tabular}

* Tiempo Post-AVE: Tiempo transcurrido desde el accidente vascular encefálico al momento de la aplicación del experimento psicolingüístico de denominación.

** Los subgrupos fueron conformados según taxonomía fluente/no fluente y perisilviana/ extrasilviana: No fluente perisilviano (NF_P), no fluente extrasilviano (NF_E), fluente perisilviano $\left(F_{-} P\right)$ y fluente extrasilviano $\left(F_{-} E\right)$. Fuente: elaboración propia.

\section{Procedimientos y materiales}

Las imágenes se presentaron a través de un procedimiento experimental psicolingüístico diseñado con el programa E-prime (Psychology Software Tools $($ ), para la captura de las grabaciones de cada respuesta, así como también para la determinación de las mediciones en milisegundos de los tiempos de respuestas de los sujetos del estudio. Los estímulos visuales fueron tomados de Snodgrass y Vanderwart (1980). Previamente a la aplicación del experimento, se procedió a explicar los propósitos de este estudio a cada participante y a su acompañante junto con la lectura del consentimiento informado, 
explicando el procedimiento en el que cada sujeto participaría.

Antes de iniciar la tarea de denominación, se hizo lectura de las instrucciones en forma lenta y clara, de manera tal de que cada sujeto tuviese absoluta claridad de la modalidad de respuesta que debía entregar. Estas instrucciones pusieron énfasis en los siguientes aspectos: modalidad de respuesta (oral), uso de una intensidad de voz apropiada y plazo de tiempo para producir la respuesta. Las instrucciones brindadas fueron las siguientes: "Ud. verá una serie de imágenes en la pantalla del computador. Ante cada imagen Ud. deberá decir el nombre de esta lo más rápido posible. Recuerde hablar alto y cerca del micrófono. Solo puede decir el nombre mientras la imagen está presente. Cuando la imagen desaparezca, concentre su atención en la próxima imagen". Cada sujeto afásico respondió a una tarea de denominación por confrontación visual de 40 imágenes representativas de 20 palabras de adquisición temprana y 20 palabras de adquisición tardía. Las 40 palabras fueron seleccionadas según índice de EdA luego de aplicar una encuesta a 45 informantes, fonoaudiólogos y estudiantes de fonoaudiología, todos con conocimientos vinculados con adquisición de palabras y desarrollo del lenguaje. La encuesta consistió en solicitar a cada informante que estableciera un índice de edad de adquisición para cada una de las 140 palabras escritas presentadas, según las siguiente escala: 1 = "La palabra fue aprendida por Ud. entre el primer y el segundo año de vida", 2 = "La palabra fue aprendida después de cumplir los 2 años de edad", 3 = "La palabra fue aprendida después de los tres años de edad" y así sucesivamente (tanto el listado de palabras como el formato de encuesta fue tomado de Cuetos et al., 1999). Estas palabras además fueron seleccionadas controlando las covariables de frecuencia léxica (FL) y longitud de palabra con base en el número de sílabas (LPNS). Los índices de frecuencia léxica fueron obtenidos del Diccionario de frecuencias de las unidades lingüísticas del castellano (Alameda \& Cuetos, 1995). Se comprobó a través de un test U de Mann-Whitney que no hubiera diferencias significativas entre ambos listados con respecto a FL y LPNS $(p=0.8816$ y $p=0.1686$, respectivamente). Con todo, se seleccionó un listado de palabras de adquisición temprana con un rango de índice de adquisición entre los 2.24 y 3.29 años de edad y un listado de palabras de adquisición tardía con un rango de índice de adquisición entre los 3.98 y 6.27 años de edad. No fue posible la selección de palabras con un índice mayor de edad de adquisición, para no afectar significativamente el índice de frecuencia léxica de las mismas y así evitar diferencias significativas entre ambos listados, entendiendo que las palabras que presentan un índice de edad de adquisición tardía muy alto disminuirían considerablemente el índice de frecuencia léxica de este grupo de palabras (Tabla 2).

TABLA 2

Listado de palabras de con edad adquisición temprana y tardía e indices respectivos

\begin{tabular}{cccc}
\hline $\begin{array}{c}\text { Palabras } \\
\text { ATe }\end{array}$ & Índice EdA & $\begin{array}{c}\text { Palabras } \\
\text { ATa }\end{array}$ & Índice EdA \\
\hline árbol & 2.58 & anillo & 4.11 \\
avión & 2.98 & bandera & 4.4 \\
caballo & 2.8 & camisa & 4.16 \\
calcetín & 2.82 & cebolla & 4.22 \\
conejo & 3.11 & cenicero & 6.27 \\
cuchara & 2.76 & cigarro & 5.24 \\
gallina & 3.11 & copa & 4.53 \\
gato & 2.24 & corbata & 4.67 \\
globo & 2.64 & flecha & 4.71 \\
lápiz & 2.64 & hacha & 5.09 \\
león & 2.93 & lámpara & 3.98 \\
manzana & 2.24 & maleta & 4.71 \\
moto & 3.29 & martillo & 4.02 \\
pantalón & 2.91 & paraguas & 4.4 \\
pera & 2.91 & pincel & 4.29 \\
plátano & 2.4 & pipa & 5.49 \\
silla & 2.58 & plancha & 3.98 \\
taza & 2.91 & regla & 4.53 \\
vaca & 2.4 & sombrero & 4.69 \\
zapato & 2.69 & trompeta & 5.24 \\
\hline & & &
\end{tabular}

Fuente: elaboración propia.

El experimento psicolingüístico se realizó a través de la presentación de 40 imágenes que fueron presentadas en dos momentos, con un breve descanso entre ellos, a través de dos series 
de 20 imágenes cada una. Cada set contenía 10 imágenes que representaban palabras de adquisición temprana (imágenes ATe) y 10 de adquisición tardía (imágenes ATa) que fueron apareciendo en forma aleatoria. Cabe señalar que, antes de cada serie, se presentaron tres estímulos a modo de ensayo, para que los sujetos se familiarizaran con la dinámica del experimento. La duración de cada estímulo fue de seis segundos, y la fijación o pantalla en blanco que establece el paso de un estímulo a otro fue de tres segundos. Las respuestas de cada uno de los sujetos quedaron grabadas en forma automática como archivos individuales para su análisis posterior. Si bien se utilizó el software de experimentación E-prime para la recolección de respuestas y la obtención de los tiempos de respuestas de las producciones entregadas por cada participante, los tiempos de respuesta fueron corroborados a través del uso del programa Audacity (Audacity ${ }^{\circledR}$, Free CrossPlatform Sound Editor), ya que en algunos casos la baja intensidad vocal de algunos sujetos no permitió, mediante el programa experimental, determinar en forma exacta el punto de inicio de la respuesta en algunas producciones.

\section{Análisis de datos}

En una planilla Excel, se transcribió cada una de las respuestas producidas por los sujetos, así como también el registro de los tiempos de respuesta para cada una de ellas. Posteriormente, se realizó la valoración con respecto a la precisión de las respuestas, cotejando si la respuesta fue acertada o errónea. Los efectos de la variable independiente edad de adquisición de palabras (EdA) fueron analizados considerando la precisión o aciertos en las respuestas y los tiempos de respuesta (TR) ante los aciertos alcanzados, medidos en milisegundos. Para un primer análisis cuantitativo, se tuvieron en cuenta todas las respuestas correctas alcanzadas por los sujetos ante el grupo de imágenes ATe y ante el grupo de imágenes ATa. Se contabilizaron las respuestas correctas alcanzadas por el grupo de estudio compuesto por los 22 sujetos, como también las alcanzadas por cada uno de los subgrupos de sujetos, conformados según la condición fluente/no fluente y perisilviana/extrasilviana, además de los subgrupos conformados a partir de la combinación de ambas taxonomías (i. e., subgrupo fluente perisilviano). Cabe señalar que para estos fines, se consideró como acierto toda aquella respuesta en la que se evidenciara la evocación de la palabra correcta, sin que fuese precedida o continuada por un error de tipo fonológico o semántico (Pashek \& Tompkins, 2002). Excepcionalmente, solo se aceptó como correcta aquella respuesta que fuese precedida por algún enunciado neutro (i. e., "haber, es un... sí, sé lo que es...), tomándose como tiempo de respuesta solo el inicio de la palabra correcta. Las respuestas que fueron precedidas o continuadas por un error, se estimaron como autocorrecciones exitosas o autocorrecciones con fracaso, según el caso, y para este análisis general fueron contabilizadas como incorrectas.

Para el análisis estadístico de los datos, se utilizó el software $\mathrm{R}$ v3.1.3. Para la variable dependiente de precisión de respuesta se ajustó un modelo de efectos mixtos con respuesta binaria, mientras que para los tiempos de respuesta (solo de los aciertos) se realizó la transformación logarítmica y se ajustó un modelo de efectos mixtos. En ambos ajustes se consideraron como efectos aleatorios a los participantes del estudio y las imágenes representativas de las palabras y como variables de efectos fijos a la edad de adquisición de las palabras y el tipo de afasia según taxonomías fluente/no fluente y perisilviano/extrasilviano (F.E: fluente extrasilviano, F.P: fluente perisilviano y NF.P: no fluente perisilviano). Por último, con la finalidad de controlar posibles efectos intervinientes, se examinaron las siguientes covariables: el tipo de afasia y la frecuencia léxica (FL). En todos los análisis, se utilizó un nivel de significancia del 0.05 . 


\section{Resultados}

Resultados de los modelos estadísticos aplicados

Ninguno de los modelos incorporó términos de interacción entre las variables de efecto fijo (EdA y tipo de afasia). De lo anterior se desprende que, tanto en el modelo de análisis de la precisión de respuesta como en el de análisis de los tiempos de respuesta, no se observó existencia de efectos generados a partir de una interacción entre la EdA y el tipo de afasia. Por tanto, el efecto de EdA estuvo presente independientemente del tipo de afasia y, a su vez, las diferencias entre las afasias fluentes extrasilvianas con las afasias fluentes perisilvianas y no fluentes perisilvianas se dieron tanto ante las imágenes ATe como ante las imágenes ATa. En ambos modelos se reflejó que tanto la edad de adquisición de la palabra como el tipo de afasia presentaron efectos estadísticamente significativos. Por su parte, de las covariables consideradas solo la frecuencia léxica fue estadísticamente significativa en el modelo de respuesta binaria (Tabla 3).

\section{TABLA 3}

Efectos fijos asociados a edad de adquisición, tipo de sujeto y frecuencia léxica

\begin{tabular}{|c|c|c|c|c|c|c|}
\hline \multirow{3}{*}{$\begin{array}{l}\text { Variable } \\
\text { Respuesta }\end{array}$} & \multirow[b]{3}{*}{ Estimado } & \multirow[b]{2}{*}{ Intercepto } & \multirow{2}{*}{$\begin{array}{c}\text { EdA } \\
\text { (Temp) } \\
\text { Tardía }\end{array}$} & \multicolumn{2}{|c|}{ Tipo (F_E) } & \multirow{2}{*}{$\begin{array}{c}\text { Frecuencia } \\
\text { Léxica }\end{array}$} \\
\hline & & & & $\mathbf{F}_{-} \mathbf{P}$ & $\mathbf{N F}_{-} \mathbf{P}$ & \\
\hline & & 20.538 & -14.924 & -33.918 & -37.955 & 0.0144 \\
\hline \multirow[t]{3}{*}{$\begin{array}{l}\text { Respuestas } \\
\text { correctas }\end{array}$} & $\begin{array}{l}\text { Error } \\
\text { Estándar }\end{array}$ & 0.8536 & 0.287 & 10.888 & 11.622 & 0.0062 \\
\hline & valor $p$ & 0.0161 & $<0.0001$ & 0.0018 & 0.0011 & 0.019 \\
\hline & Estimado & 30.487 & 0.0478 & 0.1968 & 0.2103 & \\
\hline \multirow[t]{2}{*}{$\begin{array}{l}\text { Log Tiemp } \\
\text { de Respuesta }\end{array}$} & $\begin{array}{l}\text { Error } \\
\text { Estándar }\end{array}$ & 0.0532 & 0.022 & 0.0719 & 0.0777 & \\
\hline & valor $p$ & $<0.0001$ & 0.0356 & 0.0186 & 0.018 & \\
\hline
\end{tabular}

Fuente elaboración propia.

Análisis de la precisión de respuestas

El valor negativo asociado al efecto de EdA (Tabla 3) indica que la proporción de aciertos o respuestas correctas fue significativamente menor en las respuestas ante las imágenes ATa. En cuanto a los subgrupos de sujetos analizados, los sujetos fluentes extrasilvianos obtuvieron una proporción mayor de aciertos que los sujetos fluentes perisilvianos y que los sujetos no fluentes perisilvianos, no encontrándose diferencia estadísticamente significativa entre la proporciones de aciertos de estos dos últimos subgrupos. En el caso de la covariable frecuencia léxica, el valor positivo indica que las palabras con mayor frecuencia léxica obtuvieron un mayor porcentaje de aciertos.

\section{Análisis de los tiempos de respuestas}

En la Tabla 4, podemos observar que los valores estimados son positivos y significativos, indicando que, en el caso de la EdA, el tiempo de respuesta fue estadísticamente significativamente mayor ante las imágenes ATa. En el caso del tipo de sujetos, se observó que los sujetos fluentes extrasilvianos obtuvieron un tiempo de respuesta, estadísticamente significativo, menor que los sujetos fluentes perisilvianos y no fluentes perisilvianos, y a la vez los tiempos de respuesta entre estos dos últimos grupos no presentaron diferencias estadísticamente significativas.

\section{TABLA 4}

Efectos fijos asociados a edad de adquisición, tipo de afasia y frecuencia léxica

\begin{tabular}{lllc}
\hline & Variable & Nivel & Efecto \\
\hline $\begin{array}{l}\text { Respuestas } \\
\text { correctas }\end{array}$ & EdA & Temprana & 0.483 \\
& & Tardía & 0.1736 \\
& Tipo de afasia & $\begin{array}{l}\text { Fluente } \\
\text { extrasilviana }\end{array}$ & 0.843 \\
& & $\begin{array}{l}\text { Fluente } \\
\text { perisilviana }\end{array}$ & 0.1531 \\
No fluente & 0.1077 \\
perisilviana & \\
Tiempo de & EdA & Temprana & 30.903 \\
& & $\begin{array}{l}\text { Tardía } \\
\text { Respuesta }\end{array}$ & 3.138 \\
& Tipo de afasia & $\begin{array}{l}\text { Fluente } \\
\text { extrasilviana }\end{array}$ & 30.195 \\
& & $\begin{array}{l}\text { Fluente } \\
\text { perisilviana } \\
\text { No fluente } \\
\text { perisilviana }\end{array}$ & 32.163 \\
& & 32.298 \\
\hline
\end{tabular}

Fuente: elaboración propia.

A partir de los resultados obtenidos, se puede establecer que las imágenes que representan palabras de adquisición temprana generan un 
mayor número de aciertos y un menor tiempo de respuesta, en las producciones de los sujetos afásicos en una tarea de denominación por confrontación visual, independientemente del tipo de afasia que estos presenten. No obstante, se apreciaron diferencias significativas entre los sujetos con afasias extrasilvianas y sujetos con afasias perisilvianas, apreciándose un mejor desempeño en los primeros, evidenciado en un mayor número de aciertos y en un menor tiempo de respuesta que los segundos. Así también, es posible establecer a través de este estudio que no existe una dependencia de la variable de edad de adquisición con la variable frecuencia léxica, ya que se pudo comprobar que los efectos de la edad de adquisición de las palabras son independientes de la variable frecuencia léxica, al presentarse dos listados de palabras con diferentes índices de edad de adquisición, pero sin presentar diferencias estadísticamente significativas en cuanto a frecuencia léxica. No obstante, igualmente, se pudo comprobar que las palabras con un alto índice de frecuencia léxica generan respuestas más exitosas y rápidas que las palabras con menor índice de frecuencia léxica. Dicho hallazgo nos permite proponer una hipótesis alterna relacionada con esta última variable, estableciendo que a mayor índice de frecuencia léxica, los sujetos afásicos presentan mejor desempeño en tareas de denominación por confrontación visual, representado en una mayor proporción de aciertos y menor tiempo de respuesta.

\section{Discusión}

Un análisis preliminar simple que se puede plantear, a partir de los resultados obtenidos, es el que dice relación con el hecho de que el grupo total de sujetos afásicos, sin distinción de tipo o subtipo de afasia, presentó un mayor porcentaje de aciertos y un menor tiempo de respuesta ante imágenes ATe que ante imágenes ATa. A partir de estos hallazgos, se puede establecer una mayor y exitosa activación de palabras de adquisición temprana que de palabras de adquisición tardía en una tarea de denominación por confrontación visual. Recordemos que a cada uno de los sujetos se le solicitó responder lo más rápido posible ante la presentación de cada imagen. Si consideramos que los participantes fueron sujetos con daño cerebral y que la instrucción dada antes del experimento, con énfasis en respuestas rápidas que no permite una mayor reflexión acerca de la imagen presentada, podemos plantear que las respuestas fueron generadas a partir de un proceso rápido constituido por eventos de activación en cascada (Ellis \& Young, 1988) que se inicia con el reconocimiento de la imagen y culmina con la codificación fonológica, la programación motora del habla y la correspondiente ejecución del habla de la o las palabras que conforman la respuesta. De acuerdo con este esquema, el acierto en una respuesta de denominación oral de una imagen observada es reflejo de la activación exitosa de un elemento léxico correcto y de una inhibición, también exitosa, de competidores que se encuentran en la red léxica (Scott \& Wilshire, 2010); así, un mayor porcentaje de aciertos y, a la vez, un menor tiempo de respuesta ante un determinado grupo de palabras en comparación con otro grupo de palabras, puede considerarse un indicio importante de una activación más exitosa en un caso con respecto al otro. A partir de esto, se puede establecer que si los sujetos afásicos de este estudio presentaron una activación léxica más exitosa ante imágenes ATe que ante imágenes ATa, se espera que todas aquellas palabras que poseen un índice de edad de adquisición temprana tengan una mayor probabilidad de activación exitosa en sujetos afásicos; no obstante, no podemos descuidar que las variaciones en el grado de activación estarán evidentemente relacionadas también con otros factores tales como la edad del paciente, el grado de severidad del cuadro afásico y desempeño lingüístico premórbido, entre otros.

Los resultados permiten afirmar que las palabras con edad de adquisición temprana presentan una mayor activación y una menor inhibición que las palabras con edad de adquisición tardía (Hirsh \& Ellis, 1994). En términos generales, los hallazgos de la presente investigación resultan consistentes con los de 
estudios previos en los que se halló evidencia acerca del efecto facilitador de la EdA temprana sobre la producción léxica en pacientes afásicos (Biegler et al., 2008; Brown \& Watson, 1987; Carroll \& White, 1973; Morrison et al., 1992). Es plausible, entonces, considerar que la recuperación de representaciones fonológicas constituye un punto crítico en el proceso y donde la condición de afasia produce un mayor efecto adverso. No deja de ser interesante en este contexto plantearse la pregunta acerca de cuáles son las variables que favorecen el control de ciertas palabras erróneas (competidores controlados) y que permiten la selección de una palabra correcta que logra alcanzar un umbral de activación suficiente para su producción (Dell \& O'Seaghdha, 1992). Si bien a través de este estudio se estableció una importante relación de la variable de EdA con las propiedades de activación e inhibición léxica, queda pendiente dilucidar qué variables propias de la palabra pudiesen estar incidiendo en la manifestación de signos clínicos vinculados con la propiedad de competencia léxica. Por ahora, los resultados alcanzados permiten ampliar la visión con respecto a las características de las palabras que deben ser tenidas en cuenta en la selección de ítems que serán incorporados en pruebas de evaluación del lenguaje en sujetos con daño cerebral.

La edad de adquisición aparece como una variable que claramente marca diferencias en el desempeño de sujetos con afasia; por lo tanto, su inclusión en las pruebas de evaluación del lenguaje, y no solo en tareas de denominación por confrontación visual, resultaría de gran interés para el posterior diseño de métodos terapéuticos que favorezcan estrategias de reactivación y compensación durante el proceso de rehabilitación. En el ámbito de la evaluación del lenguaje de sujetos con sospecha de alteraciones, la incorporación de la variable edad de adquisición de las palabras en el diseño de pruebas de producción del lenguaje que evalúan el desempeño en repetición, fluidez verbal y lectura oral; así como también de pruebas de comprensión que contemplan la evaluación del reconocimiento auditivo de imágenes, pareo viso verbal y comprensión del discurso oral, permitiría establecer una línea de base de desempeño bastante más detallada, necesaria para la elaboración de un plan de rehabilitación acorde a las características individuales de cada persona. En este plano, la selección más acuciosa de los estímulos que se van a utilizar en los procedimientos terapéuticos, no solo con el afán de reactivar a toda costa las funciones disminuidas, sino que también facilitar los mecanismos de compensación que se deseen instaurar en los pacientes, se torna cada vez más necesaria en el quehacer de los clínicos que lidian con condiciones que resultan tan dramáticas para la calidad de vida de las personas con daño cerebral. Sin duda, la identificación de las palabras que revisten un menor costo cognitivo en el procesamiento léxico, tanto en tareas de producción como también de comprensión, generará un beneficio inmediato en el desempeño de individuos que habitualmente presentan importantes bloqueos en sus respuestas cuando se enfrentan no solo a tareas que resultan complejas, sino que también a estímulos cuyas variables los hacen más difíciles de procesar.

En este contexto, es importante recordar que un sujeto con daño cerebral, siempre requerirá iniciar su proceso terapéutico con tareas y estímulos que tiendan a favorecer su desempeño inicial para evitar posibles bloqueos en sus respuestas. La presentación de un estímulo de fácil dominio, como una imagen ATe, contribuirá a generar una mayor posibilidad de respuesta exitosa que comenzará a cimentar el camino para enfrentar con un mayor nivel de acierto aquellos estímulos, que de ser considerados inmediatamente al inicio del proceso de rehabilitación, conllevarían un menor grado de dificultad.

Las proyecciones anteriores, tanto en el ámbito de la evaluación como de la rehabilitación, pueden y deben ser consideradas también para otras condiciones que generan una disminución en el desempeño lingüístico y cognitivo de los individuos, ya sea en el contexto del envejecimiento normal como también en el de aquellas condiciones adquiridas luego de un daño neurológico agudo, crónico o progresivo. 
Siendo así, es interesante plantear el desafío de determinar los efectos de la EdA en tareas que requieren dominio de funciones cognitivas como la atención, la memoria, las funciones visoespaciales y visoconstructivas, entre otras. La necesidad de realizar estudios psicolingüísticos en sujetos que ven entorpecido su desempeño cognitivo-comunicativo en el ámbito familiar, social, académico y/o laboral se torna cada vez más evidente, dado los importantes desafíos que implica asumir la responsabilidad de rehabilitar a una población adulta cada vez más numerosa y longeva, con riesgos importantes de padecer enfermedades cardiovasculares asociadas a los malos hábitos alimenticios y al sedentarismo. Por otro lado, existe una mayor preocupación por la calidad de vida del adulto mayor en las políticas de Estado, que invita a los profesionales y académicos a asumir la responsabilidad de aportar con mayores conocimientos desde las diferentes disciplinas, para generar los mejores programas de prevención, evaluación y rehabilitación para esta población.

\section{Agradecimientos}

Agradecimientos al Centro de Docencia Clínica del Departamento de Fonoaudiología de la Universidad de Concepción y al Centro Comunitario de Rehabilitación de San Pedro de la Paz por facilitar las dependencias para efectuar las pruebas experimentales a los sujetos del estudio.

\section{Referencias}

Alameda, J. R., \& Cuetos, F. (1995). Diccionario de frecuencias de las unidades lingüísticas del castellano. Oviedo: Servicio de Publicaciones de la Universidad de Oviedo.

Ardila, A. (2006). Las Afasias. Miami, Florida: Department of Communication Sciences and Disorders: Florida International University.
Biegler, K. A., Crowther, J. E., \& Martin, R. C. (2008). Consequences of an inhibition deficit for word production and comprehension. Cognitive Neuropsychology, 25, 493-527. https:// doi.org/10.1080/02643290701862316

Brown, G.D.A. \& Watson, F.L. (1987). First in, first out: Word learning age and spoken word frequency as predictors of word familiarity and word naming latency. Memory \& Cognition, 15, 208-216

Butterworth, B. L., Howard, D., \& McLaughlin, P. J. (1984). The semantic deficit in aphasia: The relationship between semantic errors in auditory comprehension and picture naming. Neuropsychologia, 22 (4), 409-426.

Carroll, J. B., \& White, M. N. (1973). Word frequency and age of acquisition as determiners of picture-naming latency. Quarterly Journal Experimental Psychology, 25, 85-95. https:// doi.org/10.1080/14640747308400325

Cuetos, F., Ellis, A. W., \& Alvarez, B. (1999). Naming times for the Snodgrass and Vanderwart pictures in Spanish. Behavior Research Methods, Instruments and Computers, 31, 650-658. https:// doi.org/10.3758/BF03200741

Cutler, A. (1981). Making up materials is a confounded nuisance, or: Will we be able to run any psycholinguistic experiments at all in 1990? Cognition, 10, 65-70. https:// doi.org/10.1016/0010-0277(81)90026-3

Dell, G. S. (1986). A spreading activation theory of retrieval in sentence production. Psychological Review, 93, 283-321. https:// doi.org/10.1037/0033-295X.93.3.283

Dell, G. S., \& O'Seaghdha, P. G. (1992). Stages of lexical acces in language production. Cognition, 42(1-3), 287-314.

Dell, G. S., Schwartz, M. F., Martin, N., Saffran, E. M., \& Gagnon, D. A. (1997). Lexical access in aphasic and nonaphasic speakers. Psychological Review, 104(4), 801-838.

Ellis, A. W., \& Young, A. W. (1988). Human cognitive neuropsychology. Hove, UK: Psychology Press. 
Feyereisen, P., Van der Borght, F., \& Seron, X. (1988). The operativity effect in naming: A re-analysis. Neuropsychologia, 26(3), 401-415.

González, R. (2001). Protocolo de lenguaje para pacientes afásicos. Santiago: Departamento de Neurología-Neurocirugía, Hospital Clínico de la Universidad de Chile.

Goodglass, H. (1993). Understanding aphasia. San Diego, CA: Academic Press.

Gordon, J. K., \& Kindred, N. K. (2011). Word retrieval in ageing: An exploration of the task constraint hypothesis. Aphasiology, 25, 774-788. https:// doi.org/10.1080/02687038.2010.539699

Hirsh, K. W., \& Ellis, A. W. (1994). Age of acquisition and lexical processing in aphasia: A case study. Cognitive Neuropsychology, 11(4), 435-458. https:// doi.org/10.1080/02643299408251981

Jonkers, R., \& Bastiaanse, R. (2007). Action naming in anomic aphasic speakers: Effects of instrumentality and name-relation. Brain and Language, 102(3), 262-272. https:// doi.org/10.1016/j.bandl.2007.01.002

Kertesz, A. (1985). Aphasia. En J. A. M. Frederiks (Ed.), Handbook of clinical neurology: Vol. 45. Clinical neuropsychology. Amsterdam: Elsevier.

Morrison, C. M., Ellis, A. W., \& Quinlan, P. T. (1992). Age of acquisition, not word frequency, affects object naming, not word recognition. Memory E) Cognition, 20, 705-714. https:// doi.org/10.3758/BF03202720

Nickels, L., \& Howard, D. (1995). Aphasic naming: What matters? Neuropsychologia, $33(10), 1281-1303$.

Pashek, G. V., \& Tompkins, C. A. (2002). Context and word class influences on lexical retrieval in aphasia. Aphasiology, 16(3), 261-286. https:// doi.org/10.1080/02687040143000573

Rochford, G., \& Williams, M. (1965). Studies in the development and breakdown of the use of names. IV. The effects of word frequency. Journal of Neurology, Neurosurgery, and Psychiatry, 28(5), 407-413.
Schuell, H., Jenkins, J. J., \& Carroll, J. B. (1962). A factor analysis of the Minnesota Test for the Differential Diagnosis of Aphasia. Journal of Speech and Hearing Research, 5(4), 350-369. https:// doi.org/10.1044/jshr.0504.349

Scott, R., \& Wilshire, C. (2010). Lexical competition for production in a case of nonfluent aphasia: Converging evidence from four different tasks. Cognitive Neuropsychology, 27, 505-538. https:// doi.org/10.1080/02643294.2011.598853

Snodgrass, J. G., \& Vanderwart, M. (1980). A standardized set of 260 pictures: Norms for name agreement, familiarity and visual complexity. Journal of Experimental Psychology: Human Learning 83 Memory, 6(2), 174-215.

Shapiro, L. P., Swinney, D. A., \& Borsky, S. (1998). On-line examination of language performance in normal and neurologicallyimpaired adults. American Journal of SpeechLanguage Pathology, 7, 49-60.

\section{Notas}

* Artículo de investigación. 